\title{
Evolution of Algae: Using Algae as an Art Medium to Discuss Morphology and Evolution
}

\section{Susan Wright, Dejuanna Chan, Mckenzie Riggleman, Katelyn McConaghay, Alyssa Burdick, Lyndsey Niegowski, McKenzie Bahl, and Sarah E. Ruffell}

\author{
University of Pittsburgh at Bradford, Biology Department, 300 Campus Dr, Bradford PA 16701 USA \\ (sjw80@pitt.edu; dkc19@pitt.edu; mpr39@pitt.edu; kmm295@pitt.edu; ame92@pitt.edu; \\ lgn20@pitt.edu; mjb242@pitt.edu; ruffell@pitt.edu)
}

\begin{abstract}
Engaging students through an experinetial learning activity has significant positive impacts on their interest, understanding, and knowledge retention. This experiential learning activity incorporates cross-disciplinary elements to enhance student understanding and retention of concepts related to algal evolution and morphology. This exercise is designed for students with basic knowledge of evolution and ecology or students currently enrolled in a phycology course. A pre- and post-test was used to assess concept knowledge in the areas of algal evolution and morphology. During the exercise students handle and examine algal specimens to complete written questions associated with algal morphology and evolution. Once completed, algal specimens were used to create algal pressings and paint. At the conclusion of the exercise, students possessed a greater understanding of the process of algal evolution and a higher proficiency with the morphological identification of algal phyla.
\end{abstract}

Keywords: cross-disciplinary, algae, phycology, evolution, pedagogy

Link to Supplemental Materials: https://doi.org/10.37590/able.v41.sup54

\section{Introduction}

Pedagogical research has demonstrated that cross-disciplinary design and implementation of varied learning styles can be very beneficial to student learning and content retention. Cross-disciplinary learning is the merging of components of academic disciplines, such as science and art (Segarra et al. 2018). During the exercise, students created an art piece from algal-based materials, including macroalgae and algal paints. The students used macroalgae and microalgae to examine the many morphologies present and the evolutionary differences between each organism. Incorporating this style of learning enhances student learning.

Kinesthetic-tactile learners use their hands or bodily movements to retain information (Northern Illinois University 2019). Students participating in this exercise handled different types of algae and were able to adjust their specimen. They also learned the techniques of algal pressings and paint making during the exercise. The application of kinesthetic-tactile learning allowed students to create their own relationship with the material through the specimens they were handling.

Naturalist learners examine the relationships and patterns within nature (Northern Illinois University 2019).
Students participating in the exercise identified differing morphologies of various algae phyla. Students were also made aware of the evolutionary patterns and relationships of algae. Having students participate in naturalist learning allows them to be aware of their surroundings and to acknowledge many of the unseen relationships that occur in nature.

\section{Morphology of Algae}

Algae can be divided into two categories: microalgae and macroalgae. Both microalgae and macroalgae can undergo photosynthesis and are responsible for $40-50 \%$ of the photosynthesis that occurs on Earth (Qin et al. 2012). All algae lack true plant morphologies, such as possessing roots, stems, and leaves. Macroalgae are visible to the human eye, ranging up to 30 meters in length (Bhattacharya and Medlin 1998), and have blades (leaf-like structure), stipes (stem-like structure), gas bladders and holdfasts (root-like structure) (Brooker et al. 2017). Microalgae are single-celled photosynthetic protists that are not visible to the human eye (Brooker et.al. 2017). They can possess flagella, which allows certain species of algae to be motile (Bhattacharya and Medlin 1998). 


\section{Evolutionary History of Algae}

Algae is a term used to describe photosynthetic protists. These organisms stem from six major phyla: Chlorophyta (green algae), Rhodophyta (red algae), Glaucophyta, Euglenophyta (euglena), Chlorarachniophyta, and Chromophyta (heterokonts, haptophytes, cryptomonads, and dinoflagellates) (Bhattacharya and Medlin 1998).

Evolution is known as a change in a characteristic that can be inherited by later generations (Brooker et. al. 2017). This event can produce changes in morphologies and behaviors, as well as produce new organisms (Brooker et al. 2017). Algae, more specifically, evolved through a mechanism known as endosymbiosis. This mechanism is responsible for the creation of plastids and mitochondria, which ultimately led to the algae that we see today (Keeling 2010). Endosymbiosis can occur in three different processes: primary, secondary, and tertiary. Primary endosymbiosis originally occurred 1.5 billion years ago when a heterotrophic eukaryotic cell engulfed a photosynthetic cyanobacterium (Chan and Bhattacharya 2010). From this stage, primary plastids were established, which led to the creation of the three main algae phyla: Chlorophyta, Rhodophyta, and Glaucophyta. From Chlorophyta, land plants were later established (Brooker et al. 2017). Red algal cells continued onto the second stage, secondary endosymbiosis, where they are engulfed by a new heterotrophic eukaryote. Secondary endosymbiosis leads to the creation of secondary plastids, which received their name due to the fact the plastid has more than two membrane envelopes (Brooker et al. 2017). These secondary plastids were then found within the following types of algae: diatoms, kelps, euglenoids, cryptomonads, haptophytes, chlorarachniophytes, and some dinoflagellates (Brooker et al. 2017). Tertiary endosymbiosis leads to the creation of other dinoflagellates. Tertiary endosymbiosis occurs through the engulfment of a protist with a secondary plastid by a dinoflagellate (Brooker et al. 2017). Through these three processes, all algal life was created and will continue to evolve into the future.

\section{Educational Importance}

Education on algae is important because it has many impacts on our environment and industrial practices. For example, harmful algal blooms (HABs) are a naturally occurring process that arises through the overproduction of algal cells due to an increase in nutrients. This increase of nutrients can be attributed to agricultural and industrial runoff. These blooms can negatively impact us and our environment, for if left untreated, HABs have the potential to produce cyanotoxins, which can harm, and in some cases kill, humans and animals. However, if monitored, the number of cases related to cyanotoxin poisoning can be decreased (Cyanobacterial Harmful Algal Blooms 2017). The industrial applications of algae are diverse, from fuel, nutritional supplements, textiles and cosmetics. For example, extracts found in Arthrospira sp. and C. vulgaris are commonly found within cosmetic products. Arthrospira sp. extract has been found to revert signs of premature aging and tighten the skin. C. vulgaris extracts have been found to promote collagen synthesis, which can lead to a reduction in wrinkles (Stolz and Obermayer, 2005). 


\section{Student Outline}

Safety precaution: do not participate if you are allergic to algae. Be sure to wear aprons and gloves. Be careful when placing heavy books and practice caution while using scissors to avoid injury

\section{Objectives}

- Use Spirulina algal powder provided to make green paint

- Learn the evolutionary history of Bacillariophyta, Chlorophyta, Rhodophyta, and Phaeophyta

- Hands-on experience with kelp and Rhodophyta

\section{Introduction}

You are a biology student with a passion for art, who has enrolled in a phycology course this semester. After the introductory lecture, you were amazed to learn that algae are more than just the scum that grows within your betta fish tank in your dorm room. Wanting to learn more about the morphologies between the different phyla and how they relate to algal evolution, you meet with your phycology professor during office hours. Your professor suggests creating an art piece to help deepen your understanding and to appeal to your personal interests. After your meeting, you rush back to your dorm room and research ways to include algae and art and decide to make an algal pressing. You go to Amazon ${ }^{\circledR}$ and order different types of algae, and by the end of the week your package has arrived in the mailroom. When you open the box, you have found all the labels are missing. You decide the best way to figure out the identity of each specimen is to identify them based on their morphological features. After rehydrating your algae, you lay them out on watercolor paper and use your lecture notes on algal morphology to help you identify and label each specimen. Next, you layer wax paper and cardboard over your pieces and place many textbooks on top. One week later, you decide you want to add more to your piece before showing it off to your professor. You recall finding an algae powder during your research and decide to make an algal-based paint to paint over your work. Once your piece is finished, you decide to write about the relationship between art and algal evolution. You then contact your professor to discuss your findings and display your artwork in the hallway outside of the lecture hall.

\section{Materials}

Table 1. Supplies needed by instructor and students to complete exercise.

\begin{tabular}{|c|c|c|}
\hline Pre-Lab Materials & Lab Day One Materials & Lab Day Two Materials \\
\hline Pre-lab packets (found in appendix) & 9 pairs of scissors (1 pair per person) & 9 paint brushes (1 per person) \\
\hline $\begin{array}{l}\text { lab lecture and PowerPoint (found } \\
\text { in the link to supplemental } \\
\text { materials and to be used for the } \\
\text { entire lab) }\end{array}$ & $\begin{array}{l}9 \text { large pieces of watercolor paper (1 } \\
\text { piece per person) }\end{array}$ & $\begin{array}{l}6 \text { ounces of Spirulina powder (shared } \\
\text { among all students) }\end{array}$ \\
\hline $\begin{array}{l}5 \text { large, dehydrated pieces of algae } \\
\text { (Rhodophyta, Chlorophyta, or } \\
\text { Phaeophyta) (shared among all } \\
\text { students) }\end{array}$ & $\begin{array}{l}5 \text { large, hydrated pieces of algae } \\
\text { (Rhodophyta, Chlorophyta, or } \\
\text { Phaeophyta) (shared among all students) }\end{array}$ & $\begin{array}{l}16 \text { ounces of clay powder (shared } \\
\text { among all students) }\end{array}$ \\
\hline $\begin{array}{l}\text { plastic containers with a lid (if } \\
\text { rehydrating two-three days prior) }\end{array}$ & 9 Sharpies ${ }^{\circledR}$ (1 per person) & $\begin{array}{l}\text { large beaker filled with water (shared } \\
\text { among all students) }\end{array}$ \\
\hline $\begin{array}{l}\text { Turkey roasting pan (if rehydrating } \\
\text { the day of the exercise) }\end{array}$ & 9 pairs of forceps ( 1 per person) & $\begin{array}{l}\text { plastic cups to divide paint and to hold } \\
\text { water to clean brushes (shared among } \\
\text { all students) }\end{array}$ \\
\hline $\begin{array}{l}\text { colored pencils (to be shared } \\
\text { among students and used for pre- } \\
\text { lab assignment) }\end{array}$ & 9 cardboard pieces ( 1 per person) & $\begin{array}{l}\text { gloss spray, varnish, or gel medium } \\
\text { (shared among all students) }\end{array}$ \\
\hline \multirow{2}{*}{$\begin{array}{l}\text { gloves and aprons (to be used by } \\
\text { all students while handling algae } \\
\text { during pre-lab and day one) }\end{array}$} & paper towel (shared among all students) & post-lab questions \\
\hline & at least 5 heavy books & \\
\hline
\end{tabular}

\section{Methods and Data Collection}




\section{Part A: Pre-Lab:}

A day or two before starting the lab, the instructors will provide students with a brief presentation on algal evolution and morphology. After the presentation, students will receive a pre-lab packet (found in the appendix) with three exercises discussing the material discussed. The pre-lab packet is to be completed and corrected before the students can create their piece of art. Instructors may consider having students place the algae in water beginning the rehydration process at this time to be able to see some of the morphological features of the specimens they are working with.

\section{Part B: Preparation - Day One}

After watching a brief demonstration of the pressing process, students are to put on gloves and their aprons before handling the algae. The students will receive the following: a piece of watercolor paper, macroalgae of their choosing, paper towel, sharpie marker, scissors, and forceps. Students are to sign their name on the bottom of the watercolor paper to be able to identify their work. After signing their name, the students may opt to cut their selected algae into shapes and then blot the algae mostly dry before placing it on the watercolor paper. Once the students are content with their placement, they will receive a piece of wax paper and cardboard and be instructed to continue with steps three and four shown in the timeline below (Fig. 1).

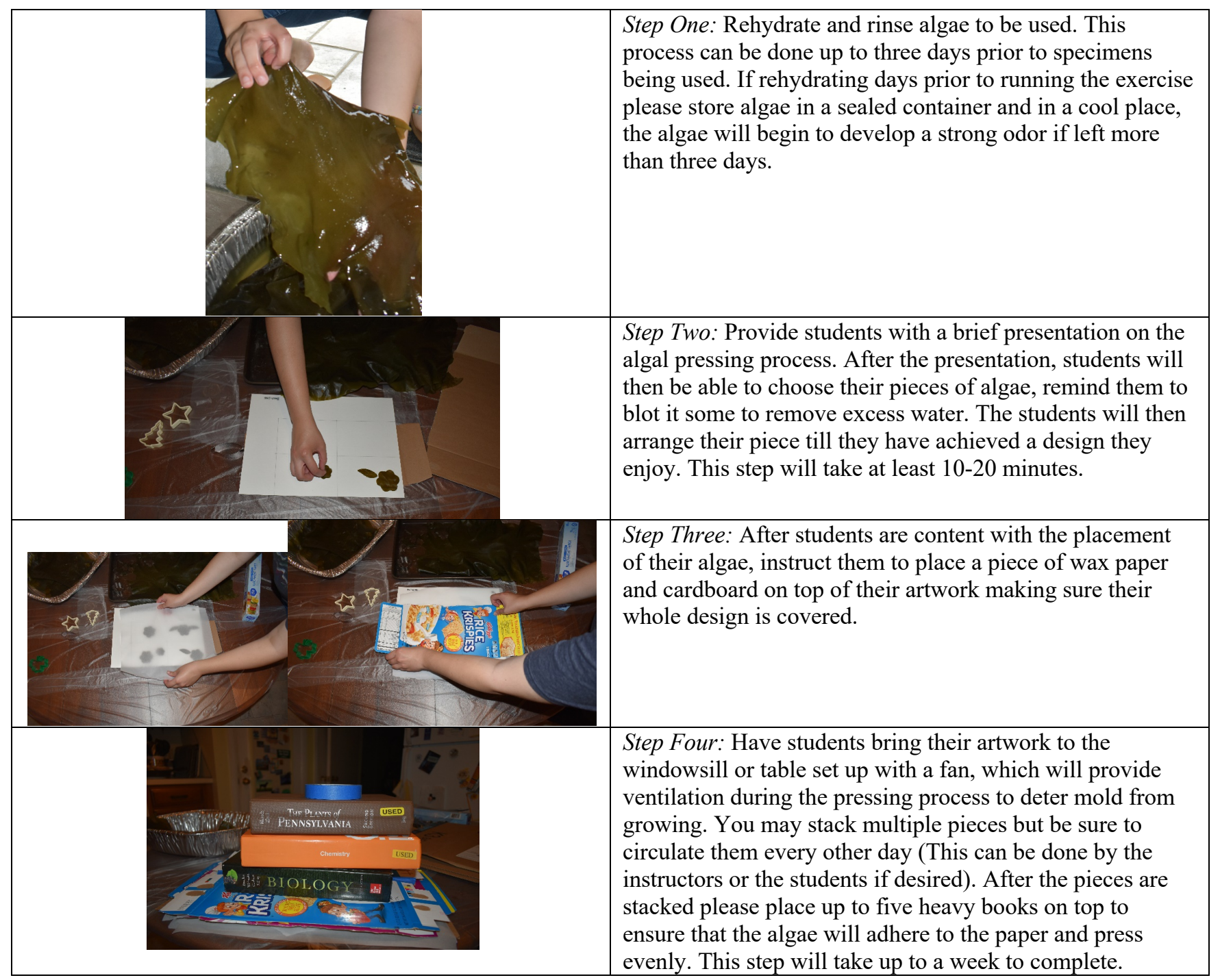

Figure 1. The process for making an algal pressing.

Part C: Painting - Day Two 
One week after the algae have been pressed, students will have the opportunity to further customize their artwork. The instructors will provide the students with brief demonstrations that include making the Spirulina paint (Fig. 2) and how to apply a gloss spray, varnish, or gel medium to seal their piece and protect it from damage. After the students finish their work, they are to answer the post-lab questions at the end of the Student Outline. At the end of the lab period, the instructors will facilitate a discussion going over the questions from the student handout. After all the art pieces have dried, the instructors will display them in the hall for all students to see. The students may collect their pieces after the display is taken down.

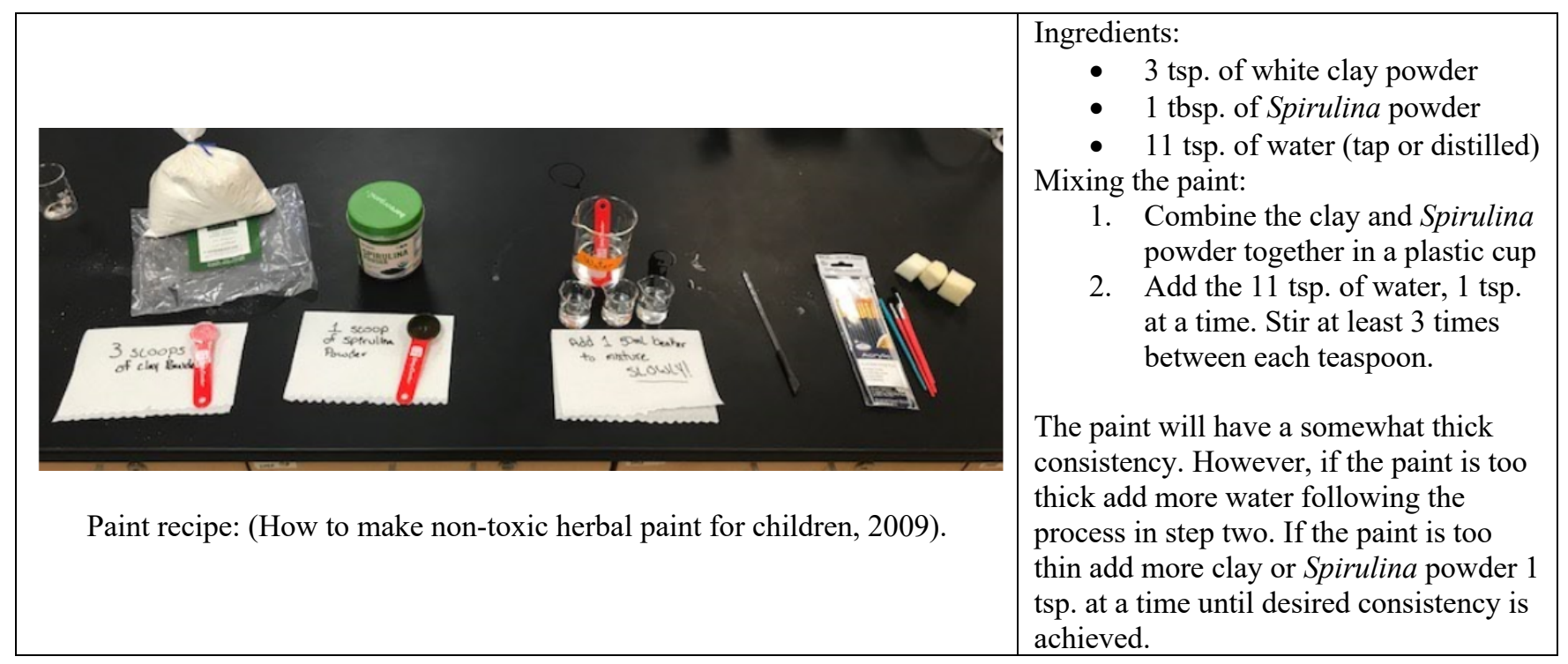

Figure 2. Algal paint recipe.

\section{Part D: Post Lab Questions}

The following two questions are to be answered after the completion of the activity. At the end of the lab period there will be a discussion that includes the answers to the following:

Question 1: Research: a famous artist that makes algae art. Specify what art form they use, type of algae, and any specific challenges that follow. (Use google for this exercise)

Question 2: Using your knowledge of algal evolution explain how this concept can be applied through art 


\section{Materials}

Please note that the macroalgae and Spirulina powder that is listed is sustainably harvested, certified USDA organic, and $100 \%$ vegan

Scissors

Watercolor Paper:

Ranger Inkssentials Watercolor Paper White, 8.5 x 11 (Pack of 10) Amazon.com: \$9.11 USD

Macroalgae

Vitamin Sea Organic Dulse whole leaf 4oz package Amazon.com: \$14.97 USD

Vitamin Sea Organic Kombu Sugar Kelp whole leaf 4oz package Amazon.com: \$14.49 USD

Vitamin Sea Organic Bladderwrack whole leaf 4oz package Amazon.com: \$13.95 USD

Vitamin Sea Organic Wakame whole leaf 4oz package Amazon.com: \$13.99 USD

Vitamin Sea Organic Sea Lettuce Seaweed

whole leaf 4oz package Amazon.com: \$14.49

USD

Spirulina Powder

DNA 707 Organic Spirulina Powder 250g

Amazon.com: \$12.75 USD

Sharpie ${ }^{\mathrm{TM}}$ Markers

Wax Paper

Cardboard Pieces

Forceps

Colored Pencils

Plastic Cups

Paper Towel

Plastic Container with a Lid

Disposable Turkey Roasting Pan (optional) Student

Handouts (found in appendix)

Paint Brushes

Darice Kid's Paint Brushes 24 pc Amazon.com:

\$3.11 USD

White Clay Powder

Monterey Bay Spice Co. Kalolin Clay Powder

1lb Amazon.com: \$9.41 USD

Gloss Spray, Varnish, or Gel Medium

Mod Podge 1470 Clear Acrylic Sealer Gloss

Spray 12oz Amazon.com: \$6.88 USD

Mod Podge Waterbase Sealer 16 oz Matte

Finish Amazon.com: \$7.44 USD

US Art Supply Clear Gel Medium Matte or

Glossy $200 \mathrm{~mL}$ tube Amazon.com: \$6.96 USD

\section{Notes for the Instructor}

\section{Common Issues}

The following three sections provide information on how to fix common issues that may occur with this exercise.

\section{Preparation}

To prepare this lab quickly, you can fill a container with cold water the day of the lab and soak the macroalgae that you will be using 15-30 minutes prior to the lab period. Be sure to rinse the macroalgae before students work with it.

\section{Cost}

To decrease the cost of supplies needed, please consider having the students work in small groups. Groups can be up to 4 people large; be sure to give each person a specific task during the process to ensure that each member can participate in the exercise.

\section{Mold}

To prevent mold from forming, be sure to place the artwork in a well-vented place, like in front of a window. In the case of inclement weather, place a fan in front of the artwork being pressed. Also, be sure to check (or have students check) the artwork at least every other day, and to circulate the pieces if pressing multiple pieces under the same set of books. To circulate the pieces, simply place the top piece on the bottom and continue doing this to the whole stack. It is best to limit the number of pieces per stack to 3-4 if pressing under the same set of textbooks.

\section{Modifications for Lab Exercise}

The following sections provide some modifications that can be made to the lab if desired.

For Algal Pressings

Consider allowing students to use cookie cutters or decorative scissors to create patterns and shapes. This will also allow students to be more creative in the piece that they Makkie Cutters: Wilton Cookie Cutters 101

Piece Set Amazon.com: \$9.19 USD

Decorative Scissors: Emraw Craft Scissors Pack of 6 Amazon.com: \$11.49 USD

\section{For Algal Paint}

If short on time, you may use a pouring medium to turn the Spirulina powder into paint instantly. If using the pouring medium, the recipe is as follows: for every 4 oz of liquid pouring medium use 3 tablespoons of Spirulina powder. You can also change the tint of the paint if using the pouring medium by adding in acrylic paints (the ratio is 3 drops for every $4 \mathrm{oz}$ of Spirulina paint). 
Pouring Medium: 349620 Color Pour Pouring Medium Clear or White 8 oz Hobbylobby.com: \$7.99 USD

\section{Displaying Artwork}

To have a more professional display of the artwork you can do any of the following ideas:

Place pieces in frames

Create a shadow box piece

Algal collage using multiple types of macroalgae and paints made from microalgae

Making jewelry by adhering the pressed pieces to the backs of glass pendants

\section{Cited References}

Activity: making algae presses. c2019. Manoa (HI): University of Hawaii at Manoa - Exploring our fluid earth; [accessed 2019 Aug 8]. https://manoa.hawaii.edu/exploringourfluidearth/ biological/aquatic-plants-and-algae/evidencecommon-ancestry-and-diversity/activity-makingalgae-presses

Bhattacharya D and Medlin L. 1998. Algal phylogeny and the origin of land plants. Plant Physiology. [accessed 2019 Aug 14]; 116(1): 9-15. http://www.plantphysiol.org/content/116/1/9. doi: $10.1104 /$ pp.116.1.9

Brooker BJ, Widmaier EP, Graham LE, Stiling PD. 2017. Biology 4th edition. New York: McGraw-Hill Education.

Chan CX and Bhattacharya D. 2010. The origin of plastids. Nature Education. [accessed 2019 Aug 14]; 3(9):84.

https://www.nature.com/scitable/topicpage/theorigin-of-plastids-14125758/

Cyanobacterial Harmful Algal Blooms (CyanoHABs) in water bodies. 2017 Jan. 19. Washington DC: United States Environmental Protection Agency - Environmental Topics; [updated 2019 July 18; accessed 2019 Aug 8]. https://www.epa.gov/cyanohabs

Darwin C. 2004. The Origin of Species. New York: Barnes and Noble Books.

How to make non-toxic herbal paint for children. c.2009. DIY Natural. [updated 2013 July 11; accessed 2019 Aug 14]. https://www.diynatural.com/homemade-paintfor-kids/
Instructional Guide for University Faculty and Teaching Assistants. c2019. DeKalb (IL): Northern Illinois University - Faculty Development and Instructional Design Center [updated 2016 Jan 5; cited 2019 Sept. 16].

https://www.niu.edu/facdev/resources/guide/inde X.shtml.

Keeling PJ. 2010. The endosymbiotic origin, diversification and fate of plastids. Philosophical Transactions B. [accessed 2019 Aug 14]; 365(1541): 729-748. https://www.ncbi.nlm.nih.gov/pmc/articles/PMC 2817223/. doi: 10.1098/rstb.2009.0103.

Kelman D, Posner EK, McDermid KJ, Tabandera NK, Wright PR, Wright AD. 2012. Antioxidant activity of Hawaiian marine algae. Drugs. [accessed 2019 Aug 11]; 10(2):403-416. https://www.mdpi.com/1660-3397/10/2/403. doi:10.3390/md10020403.

Kunstformen der Natur. c2019. Cardiff (Wales): National Museum Wales - Amgueddfa Blog; [updated 2013 Aug 23; Cited 2019 Aug 8]. https://museum.wales/blog/2013-0823/Kunstformen-der-Natur--/

Kutschera U, Levit GS, Hossfeld U. 2019. Ernst Haeckel (1834-1919): the German Darwin and his impact on modern biology. Theory in Biosciences. [accessed 2019 Aug 10]; 138(1):1-7. https://link.springer.com/article/10.1007/s12064019-00276-4. doi: 10.1007/s12064-019-00276-4.

Qin S, Lin H, Jiang P. 2012. Advances in genetic engineering of marine algae. Biotechnology advances. [accessed 2019 aug 19]; 30(6):16021613.https://www.sciencedirect.com/science/arti cle/pii/S0734975012001048. doi: 10.1016/j.biotechadv.2012.05.004.

Segarra VA, Natalizo B, Falkenberg CV, Pulford S, Holmes RM. 2018. STEAM: using the arts to train well-rounded and creative scientists. Journal of Microbiology and Biology Education. [accessed 2019 Aug 10]; 19(1): 19.1.53. https://www.ncbi.nlm.nih.gov/pmc/articles/PMC 5969448/. doi: 10.1128/jmbe.v19i1.1360.

Stolz P and Obermayer B. 2005. Manufacturing microalgae for skin care. Cosmetics \& Toiletries. [accessed 2019 Aug 14]; 120(3):99. http://connection.ebscohost.com/c/articles/16295 351/manufacturing-microalgae-skin-care. 


\section{Acknowledgments}

Thank you to Assistant Professor Anna Lemnitzer for helping with final presentation of finished algal work.

\section{About the Authors}

Susan Wright is a senior at the University of Pittsburgh at Bradford. She is currently pursuing a degree in biology. Her future goal is to work at the National Institute of Environmental Health and Science, examining the effects of the environment on public health.

Dejuanna Chan is a senior pursuing a B.S with a minor in chemistry at the University of PittsburghBradford. She has won the sophomore excellence award and Deans list since 2016. She is graduating April 2019.

McKenzie Riggleman is a graduate of Altoona Area High School. McKenzie is currently pursuing a bachelor's degree in biology with a minor in chemistry at the University of Pittsburgh at Bradford. She has had 8 years of experience as a medical secretary. Her interests are in the medical and environmental fields.
Katelyn McConaghay is a senior at the University of Pittsburgh at Bradford, majoring in Biology. Where she is obtaining a degree in the biological sciences in hopes of later obtaining a job focusing more on the environmental/ outdoor aspects of her field of study.

Alyssa Burdick graduated Northern Potter Jr. Sr. High school and is currently attending University of Pittsburgh at Bradford majoring in biology.

Lyndsey Niegowki attends the University of Pittsburgh at Bradford and is currently a junior biology major.

McKenzie Bahl graduated from University of Pittsburgh at Bradford with a biology degree, and she will pursue a career in conservation biology researching endangered wildlife to prevent extinction.

Sarah E. Ruffell is an Assistant Professor at the University of Pittsburgh at Bradford. Her areas of focus include, science education, community outreach, and microbiology. As of 2020, she has begun a new position at the University of Waterloo and would be happy to answer any questions you have at her new email sruffell@uwaterloo.ca 


\section{Appendix A: Student Handouts}

\section{KELP I'M PRESSED!}

\section{Looking at Algal Evolution \\ Through Art \\ PRE-LAB PACKET}

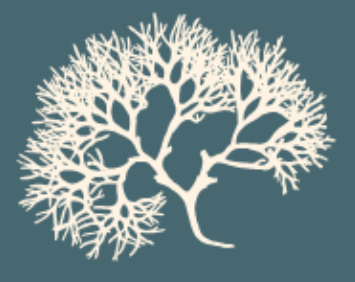

NAME:

DATE:

Algae have been on Earth for Around 3.5 billion years. So far in it's lifespan, it has become a vital organism within Earth's ecosystem. But how did algae come to be? The three following exercises will help explain the evolutionary history of algae.

\section{EXERCISE ONE:}

Algae originally evolved through a process known as endosymbiosis. Please explain the steps and events taking place within the following diagram

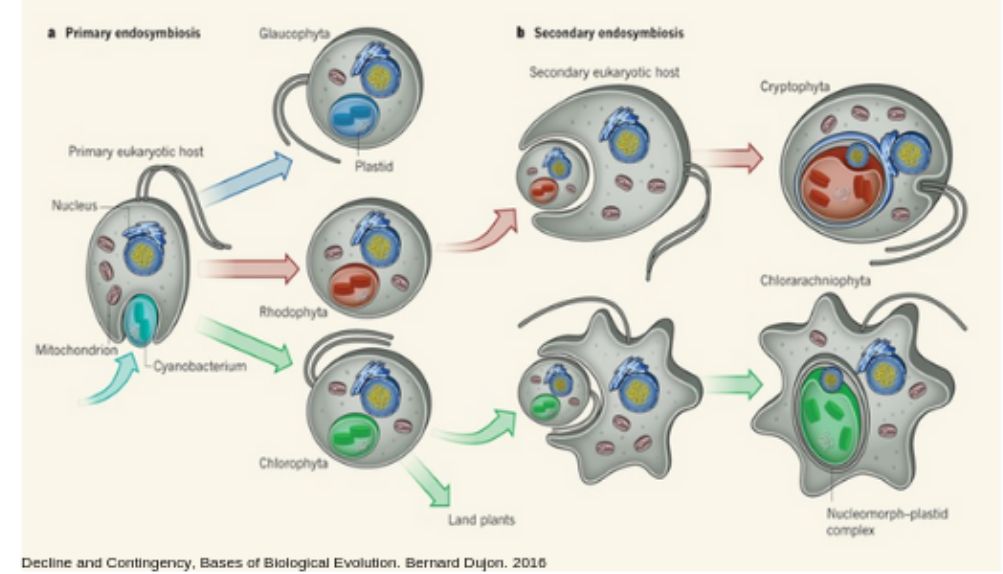


EXERCISE TWO:

Match the group correctly with its descriptions by writing the letter and numeral in the box (Use http://www.algaebase.org/ to find information about each group).

\begin{tabular}{|c|c|c|}
\hline $\begin{array}{l}\text { Letter: } \\
\text { Numeral: }\end{array}$ & $\begin{array}{l}\text { A. This group consists of about } \\
1,000 \text { species, most of which live in } \\
\text { marine environments. This group } \\
\text { has cell walls made of cellulose in a } \\
\text { gelatinous matrix, chlorophylls a \& } \\
\text { d, and phycobilin. }\end{array}$ & $\begin{array}{c}\text { I. Evolved } 150-200 \text { million years } \\
\text { ago }\end{array}$ \\
\hline $\begin{array}{l}\text { Green Algae } \\
\text { Letter: } \\
\text { Numeral: }\end{array}$ & $\begin{array}{l}\text { B. This group consists of about } \\
2,000 \text { species that are mostly } \\
\text { multicellular. This group is the } \\
\text { largest sized algae and is made of a } \\
\text { cellulose cell wall, chlorophylls a \& } \\
\text { c, and fucoxanthin. }\end{array}$ & $\begin{array}{c}\text { II. Evolved } 150-200 \text { million years } \\
\text { ago }\end{array}$ \\
\hline $\begin{array}{l}\text { Letter: } \\
\text { Numeral: }\end{array}$ & $\begin{array}{l}\text { C. This group contains about } \\
10,000 \text {, mostly freshwater, species. } \\
\text { This groups defining feature is that } \\
\text { many of its species are flagellated. } \\
\text { Algae in this category contain } \\
\text { chlorophylls a \& b and are } \\
\text { ancestors to all plants. }\end{array}$ & III. Evolved 1.6 billion years ago \\
\hline $\begin{array}{l}\text { Brown Algae } \\
\text { Letter } \\
\text { Numeral: }\end{array}$ & $\begin{array}{l}\text { D. This group contains about } \\
50,000 \text { species that are found in all } \\
\text { ecosystems. Organisms in this } \\
\text { group have silica cell walls ( } \mathrm{SiO} 2), \\
\text { chlorophylls a \& } \mathrm{c} \text {, and } \\
\text { fucoxanthin. }\end{array}$ & IV. Evolved 400 million years ago \\
\hline
\end{tabular}




\section{EXERCISE THREE:}

Using the colored pencils supplied, draw an example algal specimen for each group below, write full scientific name in box (Use http://www.algaebase.org/search/images/ to look up images)

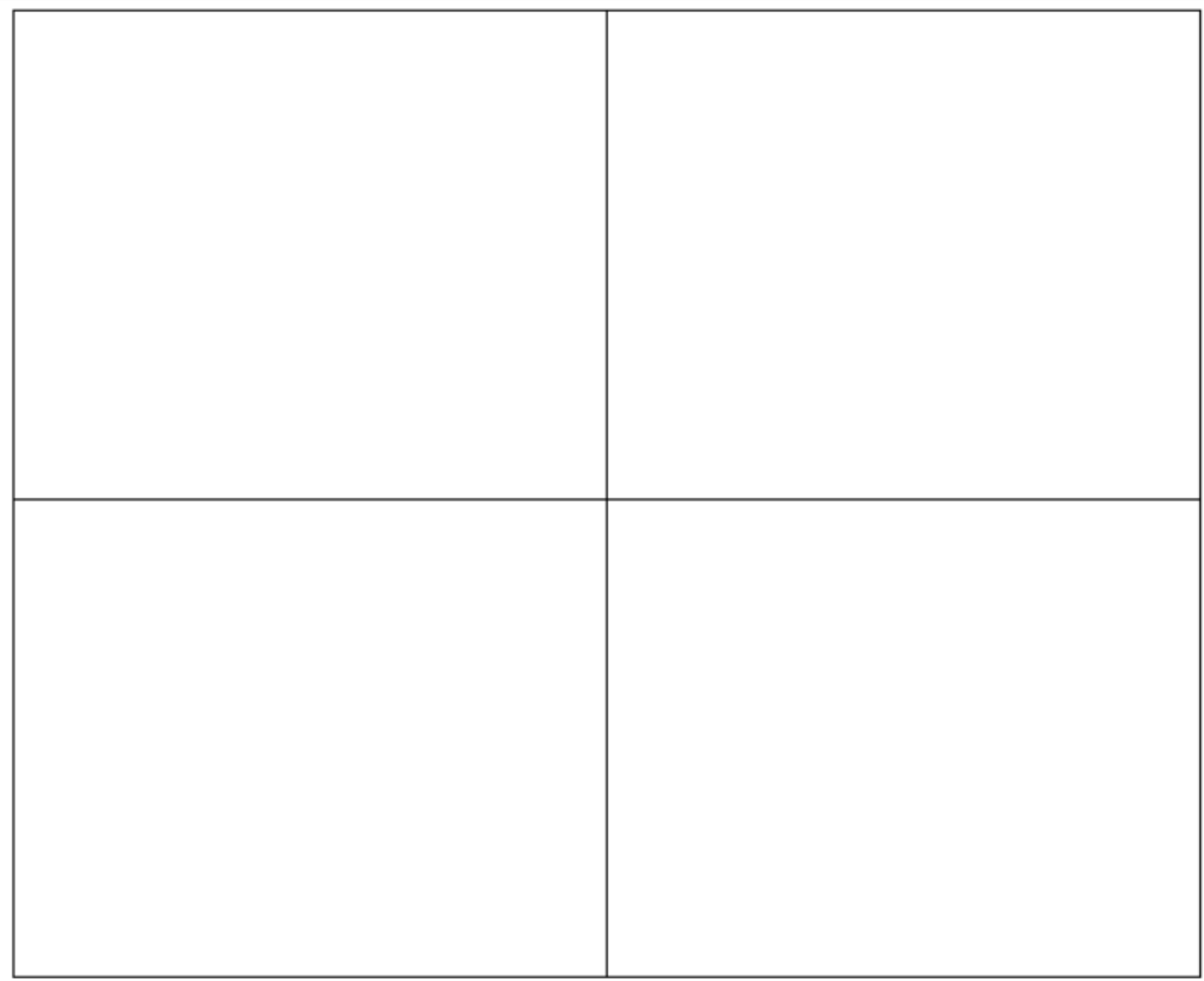




\section{KELP I'M PRESSED!}

\section{Looking At Algal Evolution} Through Art

Algae have been around for around 3.5 billion years. During its history, many of the species have been used to create art through algal pressings like the ones you are making. Algae can also be found in art supplies such as paint, where it supplies a pigment. The following questions are to be answered after you have completed your piece of algal art.

\section{QUESTION ONE:}

Research: a famous artist that makes algae art. Specify what art form they use, type of algae, and any specific challenges that follow. (Use google for this exercise)

QUESTION TWO:

Using your knowledge of algal evolution explain how this concept can be applied through art 


\section{Appendix B: Instructor's Key to Handouts}

\section{RELP IM PRESSED!}

Looking at Algal Evolution

Through Art

PRE-LAB PACKET

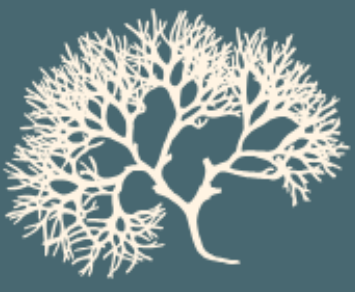

NAME:

DATE :

Algae have been on Earth for Around $\mathbf{3 . 5}$ billion years. So far in it's lifespan, it has become a vital organism within Earth's ecosystem. But how did algae come to be? The three following exercises will help explain the evolutionary history of algae.

\section{EXERCISE ONE:}

Algae originally evolved through a process known as endosymbiosis. Please explain the steps and events taking place within the following diagram

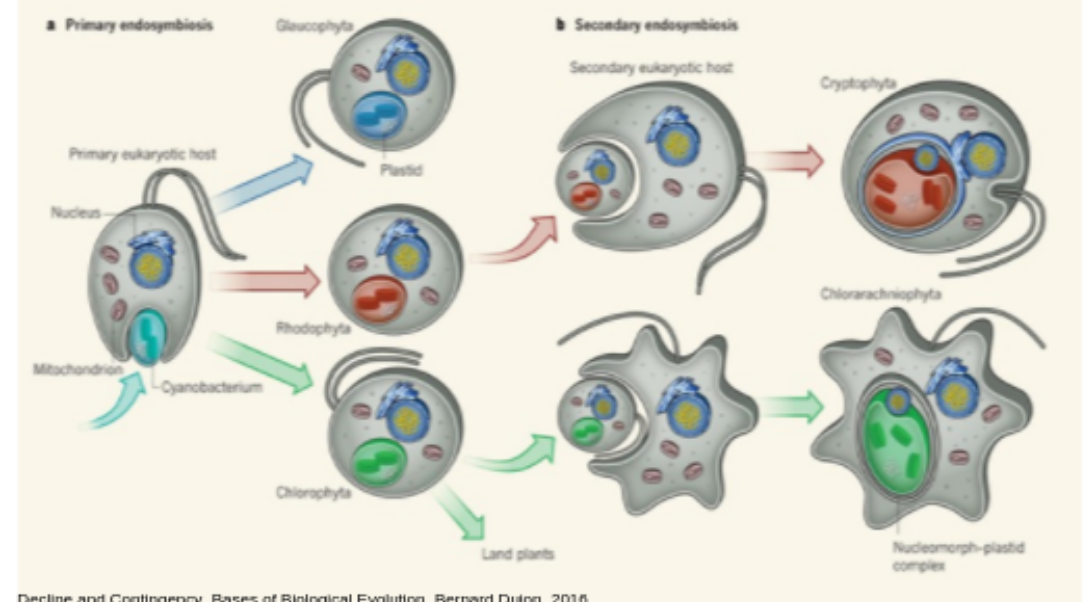

Example Answer:

This image is depicting the evolutionary pattern of algae through endosymbiosis. About 1.5

billion years ago a non-photosynthetic eukaryote engulfed a photosynthetic cyanobacterium. Leading to the three phyla of algae: Glaucophyta, Rhodaphyta, and chlorophyta. The creation of chlorophyta later leads to the creation of land plants. After primary endosymbiosis, the red and green algal cells were engulfed by a new eukaryotic heterotroph. In the red algal cell, the nucleus and mitochondria are lost and the chloroplast remains. This event has led to the creation of diatoms and chlorophytes. When comparing green algae and diatoms there are at least one billion years of distinct evolutionary history between them. 
EXERCISE TWO:

Match the group correctly with its descriptions by writing the letter and numeral in the box (Use http://www.algaebase.org/ to find information about each group).

\begin{tabular}{|c|c|c|}
\hline $\begin{array}{l}\text { Diatoms } \\
\text { Letter: } D \\
\text { Numeral: } I\end{array}$ & $\begin{array}{l}\text { A. This group consists of about } \\
1,000 \text { species, most of which live in } \\
\text { marine environments. This group } \\
\text { has cell walls made of cellulose in a } \\
\text { gelatinous matrix, chlorophylls a \& } \\
\text { d, and phycobilin. }\end{array}$ & $\begin{array}{c}\text { I. Evolved } 150-200 \text { million years } \\
\text { ago }\end{array}$ \\
\hline $\begin{array}{l}\text { Green Algae } \\
\text { Letter: } C \\
\text { Numeral: III }\end{array}$ & $\begin{array}{l}\text { B. This group consists of about } \\
2,000 \text { species that are mostly } \\
\text { multicellular. This group is the } \\
\text { largest sized algae and is made of a } \\
\text { cellulose cell wall, chlorophylls a \& } \\
\text { c, and fucoxanthin. }\end{array}$ & $\begin{array}{l}\text { II. Evolved } 150-200 \text { million years } \\
\text { ago }\end{array}$ \\
\hline $\begin{array}{l}\text { Red Algae } \\
\text { Letter: A } \\
\text { Numeral: } N\end{array}$ & $\begin{array}{l}\text { C. This group contains about } \\
10,000, \text { mostly freshwater, species. } \\
\text { This groups defining feature is that } \\
\text { many of its species are flagellated. } \\
\text { Algae in this category contain } \\
\text { chlorophylls a \& b and are } \\
\text { ancestors to all plants. }\end{array}$ & III. Evolved 1.6 billion years ago \\
\hline $\begin{array}{l}\text { Brown Algae } \\
\text { Letter: B } \\
\text { Numeral: II }\end{array}$ & $\begin{array}{l}\text { D. This group contains about } \\
50,000 \text { species that are found in all } \\
\text { ecosystems. Organisms in this } \\
\text { group have silica cell walls ( }(\mathrm{iO} 2), \\
\text { chlorophylls a \& } \mathrm{c} \text {, and } \\
\text { fucoxanthin. }\end{array}$ & IV. Evolved 400 million years ago \\
\hline
\end{tabular}




\section{EXERCISE THREE:}

Using the colored pencils supplied, draw an example algal specimen for each group below, write full scientific name in box (Use http://www.algaebase.org/search/images/ to look up images)

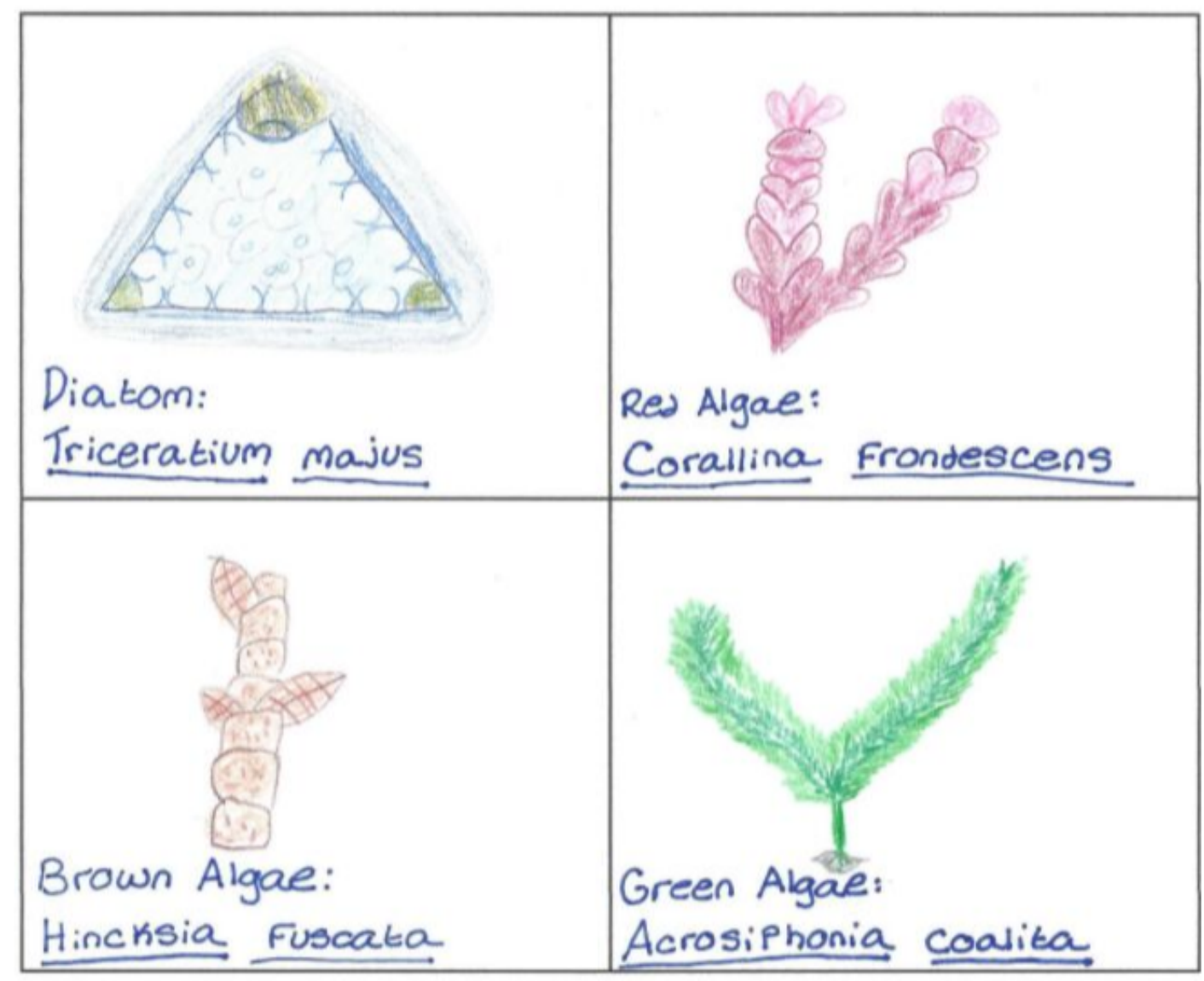

On the back of this page explain some of the interesting morphological features of the algae you chose to draw

\section{Example Answer:}

Acrosiphonia coalita is green in color, and uses a hold fast (root-like structure) to attach itself to rocks. The stipe (stem-like structure) has a feather-like appearance. 
KELP I'M PRESSED!

\section{Looking At Algal Evolution}

Through Art

POST-LAB EXERCISES

NAME:

DATE:

Algae have been around for around 3.5 billion years. During its history, many of the species have been used to create art through algal pressings like the ones you are making. Algae can also be found in art supplies such as paint, where it supplies a pigment. The following questions are to be answered after you have completed your piece of algal art.

\section{QUESTION ONE:}

Research: a famous artist that makes algae art. Specify what art form they use, type of algae, and any specific challenges that follow. (Use google for this exercise)

\section{Example Answer:}

Gu Wenda is a contemporary artist from China who paints with algal-based paints. His piece was used to bring awareness to the Harmful Algal Blooms that affect China every summer. For this piece he included 1,500 children to paint along side of him. He chose children because he wanted to teach them the importance of caring for their environment.

\section{QUESTION TWO:}

Using your knowledge of algal evolution explain how this concept can be applied through art

\section{Example Answer:}

This concept can be applied to art through the examination of the morphological features that have come over time. It is also important to note that the three main phyla of algae have emerged through primary endosymbiosis, and the differences between them such as color. 


\section{Mission, Review Process \& Disclaimer}

The Association for Biology Laboratory Education (ABLE) was founded in 1979 to promote information exchange among university and college educators actively concerned with teaching biology in a laboratory setting. The focus of ABLE is to improve the undergraduate biology laboratory experience by promoting the development and dissemination of interesting, innovative, and reliable laboratory exercises. For more information about ABLE, please visit http://www.ableweb.org/.

Advances in Biology Laboratory Education is the peer-reviewed publication of the conference of the Association for Biology Laboratory Education. Published articles and extended abstracts are evaluated and selected by a committee prior to presentation at the conference, peer-reviewed by participants at the conference, and edited by members of the ABLE Editorial Board. Published abstracts are evaluated and selected by a committee prior to presentation at the conference.

\section{Citing This Article}

Wright S, Dejuanna C, Riggleman M, McConaghay K, Burdick A, Niegowski L, Bahl M, Ruffell SE 2020. Evolution of algae: Using algae as an art medium to discuss morphology and evolution. Article 54 In: McMahon K, editor. Advances in biology laboratory education. Volume 41. Publication of the 41st Conference of the Association for Biology Laboratory Education (ABLE). https://doi.org/10.37590/able.v41.art54

Compilation (C) 2020 by the Association for Biology Laboratory Education, ISBN 1-890444-17-0. All rights reserved. Nopart of this publication may be reproduced, stored in a retrieval system, or transmitted, in any form or by any means, electronic, mechanical, photocopying, recording, or otherwise, without the prior written permission of the copyright owner.

ABLE strongly encourages individuals to use the exercises in this volume in their teaching program. If this exercise is used solely at one's own institution with no intent for profit, it is excluded from the preceding copyright restriction, unless otherwise noted on the copyright notice of the individual chapter in this volume. Proper credit to this publication must be included in your laboratory outline for each use; a sample citation is given above. 